\title{
Cirsium japonicum Flavones Enhance Adipocyte Differentiation and Glucose Uptake in 3T3-L1 Cells
}

\author{
Zhiyong Liao, ${ }^{*, a}$ Zhihua $\mathrm{Wu}^{b}$ and Mingjiang $\mathrm{Wu}^{a}$ \\ ${ }^{a}$ College of Life and Environmental Science, Wenzhou University; Wenzhou 325035, China: and ${ }^{b}$ State Key Laborato- \\ ry of Food Science and Technology, Sino-German Joint Research Institute, Nanchang University; Nanchang 330047, \\ China. Received October 14, 2011; accepted February 22, 2012
}

\begin{abstract}
Cirsium japonicum flavones have been demonstrated to possess anti-diabetic effects in diabetic rats, but the functional mechanism remains unknown. The nuclear receptor peroxisome proliferator-activated receptor $\gamma(\operatorname{PPAR} \gamma)$ plays an important role in glucose and lipid homeostasis. In this study, we report the effects of Cirsium japonicum flavones (pectolinarin and 5,7-dihydroxy-6,4-dimethoxy flavone) on PPAR $\gamma$ activation, adipocyte differentiation, and glucose uptake in 3T3-L1 cells. Reporter gene assays and Oil Red O staining showed that Cirsium japonicum flavones induced PPAR $\gamma$ activation and enhanced adipocyte differentiation of 3T3-L1 cells in a dose-dependent manner. In addition, Cirsium japonicum flavones increased the expression of PPAR $y$ target genes, such as adiponectin and glucose transporter 4 (GLUT4), and enhanced the translocation of intracellular GLUT4 to the plasma membrane. In mature 3T3-L1 adipocytes, Cirsium japonicum flavones significantly enhanced the basal and insulin-stimulated glucose uptake. The flavones-induced effects in 3T3-L1 cells were abolished by the PPAR $y$ antagonist, GW9662, and by the phosphatidylinositol 3-kinase (PI3K) inhibitor, wortmannin. This study suggests that Cirsium japonicum flavones promote adipocyte differentiation and glucose uptake by inducing $\operatorname{PPAR} \gamma$ activation and then modulating the insulin signaling pathway in some way, which could benefit diabetes patients.
\end{abstract}

Key words Cirsium japonicum; flavone; peroxisome proliferator-activated receptor $\gamma$; adipocyte differentiation; adiponectin; glucose transporter 4

Adipocytes play a major role in energy homeostasis. Excess numbers of adipocytes or enlarged adipocyte size is the hallmark of obesity, which is a major risk factor for the development of type II diabetes (T2DM). ${ }^{1,2)}$ Strict regulation of adipocyte differentiation and adipogenesis is essential for preventing obesity. Peroxisome proliferator-activated receptor $\gamma(\mathrm{PPAR} \gamma)$ is one of the most important regulators of adipocyte differentiation, ${ }^{3)}$ and is predominantly expressed in adipose tissue as a transcription factor belonging to a subfamily of nuclear hormone receptors. ${ }^{4)}$ Studies have shown that $\operatorname{PPAR} \gamma$ enhances insulin sensitivity by increasing the numbers of insulin-sensitive adipocytes, ${ }^{5)}$ or by regulating the expression of a number of genes such as adiponectin and glucose transporter 4 (GLUT4), which are involved in the regulation of the insulin signaling pathway in adipocytes. ${ }^{6}$ Both adiponectin and GLUT4 mediate glucose uptake and lipid metabolism in insulin-responsive tissues such as adipose tissue, which is essential for the maintenance of whole-body glucose homeostasis. ${ }^{7)}$ The role of PPAR $\gamma$ in the development and treatment of diabetes has been well established by several research groups. ${ }^{8-10)}$ Loss-of-function mutations in the PPAR $\gamma$ gene caused severe lipodystrophy and diabetes, indicating the importance of PPAR $\gamma$ in metabolism. ${ }^{11,12)}$ Thus, PPAR $\gamma$ has been identified as an appropriate target for pharmacological interventions for treating diabetes. ${ }^{13)}$

More and more compounds isolated from natural plants have been reported to activate PPAR $\gamma$, thereby enhancing insulin sensitivity and promoting adipocyte differentiation. ${ }^{14-18)}$ Cirsium japonicum is a wild perennial herb that has been widely used as an antihemorrhagic and diuretic agent. Flavonoid compounds are the major chemical content in Cirsium japonicum. It has been reported that Cirsium japonicum flavones exert antimicrobial, antioxidant and antitumor effects. ${ }^{19,20)}$ While scientists reported that the methanol and water extracts from Cirsium japonicum roots possess antioxidant and antidiabetic effects by inhibiting alpha-glucosidase activity, ${ }^{21)}$ our lab demonstrated in diabetic rats the anti-diabetic effect of two flavones, pectolinarin and 5,7-dihydroxy-6,4-dimethoxy flavone (DDMF), isolated from Cirsium japonicum. ${ }^{22)}$ However, the functional mechanism remains unknown. In the present study, we investigated the effect of Cirsium japonicum flavones on adipocyte differentiation and glucose uptake in 3T3-L1 cells. Our research revealed that Cirsium japonicum flavones stimulated adipocyte differentiation and enhanced glucose transport in adipocytes by inducing the PPAR $\gamma$ mediated expression of adiponectin and translocation of GLUT4 vesicles in 3T3-L1 adipocytes.

\section{MATERIALS AND METHODS}

Materials PPAR $\gamma$-luciferase reporter plasmid, fetal bovine serum (FBS), Dulbecco's modified Eagle's medium (DMEM), penicillin and streptomycin were from Invitrogen. Dexamethasone (DEX), 3-isobutyl-methylxanthine (IBMX), insulin, GW9662, Wortmannin, Oil Red $\mathrm{O}$ and $\left[2-{ }^{3} \mathrm{H}\right]$ deoxyglucose were from Sigma (St. Louis, MO, U.S.A). Rosiglitazone was purchased from Alexis Biochemicals (San Diego, CA, U.S.A.). Polyclonal antibodies against GLUT4, adiponectin, glyceraldehyde-3-phosphate dehydrogenase (GAPDH) and horse-radish peroxidase (HRP)-linked anti-rabbit immunoglobulin $\mathrm{G}(\mathrm{IgG})$ were from Cell Signaling Technology Inc. (Beverly, MA, U.S.A.). Trizol reagent, Qiagen RNeasy MinElute cleanup kit, QuantiTect SYBR Green reverse transcription-polymerase chain reaction (RT-PCR) Kit and luciferase reporter assay systems were from Promega (San Luis Obispo, CA, U.S.A.). Pierce $^{\circledR}$ bicinchoninic acid (BCA) Protein Assay kit and enhanced chemiluminescence reagent were from Pierce Biotechnology, U.S.A. FuGENE ${ }^{\circledR} 6$ transfection reagent was from 


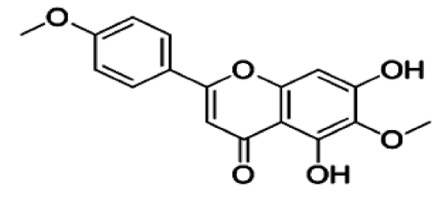

5,7-dihydroxy-6,4-dimethoxy flavone

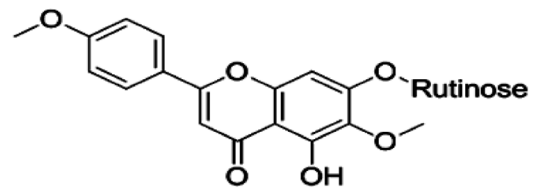

Pectolinarin

Fig. 1. Chemical Structure of Pectolinarin and 5,7-Dihydroxy-6,4-dimethoxy Flavone (DDMF)

Roche (Mannheim, Germany). Pectolinarin and DDMF were previously prepared in our lab ${ }^{22)}$ (structure shown in Fig. 1).

Cell Culture and Reporter Gene Assay Mouse 3T3-L1 preadipocytes were obtained from Cell Resources Center, Shanghai Institutes for Biological Sciences, Chinese Academy of Sciences, and cultured in DMEM supplemented with $10 \%$ FBS, $100 \mathrm{U} / \mathrm{mL}$ penicillin and $100 \mu \mathrm{g} / \mathrm{mL}$ streptomycin at $37^{\circ} \mathrm{C}$ in a humidified $5 \% \mathrm{CO}_{2}$ atmosphere. 3T3-L1 preadipocytes grown in 24-well plates were transfected with a PPAR $\gamma$ luciferase reporter plasmid and $\beta$-gal plasmid using FuGENE ${ }^{\circledR}$ 6 transfection reagent. Twenty-four hours after transfection, cells were treated with or without Cirsium japonicum flavones for another $24 \mathrm{~h}$. Cells were collected, washed once with phosphate buffered saline (PBS), and lysed with ice-cold buffer I $(25 \mathrm{~mm}$ Tris- $\mathrm{HCl}, \mathrm{pH} 7.4,150 \mathrm{~mm} \mathrm{NaCl}, 1 \mathrm{~mm}$ ethylenediaminetetraacetic acid (EDTA), 1\% Triton X-100, protease inhibitors and $2 \mathrm{~mm}$ dithiothreitol (DTT)). Lysates were centrifuged at $15000 \times \boldsymbol{g}$ at $4^{\circ} \mathrm{C}$ for $20 \mathrm{~min}$. Reporter activity in the supernatant was analyzed with luciferase reporter assay systems. The data was normalized for transfection efficiency with galactosidase activity. All the data represent an average of at least three independent assays.

Adipocyte Differentiation and Adipogenesis After reaching confluency, adipocyte differentiation was initiated by culturing 3T3-L1 preadipocytes in medium I (DMEM containing $0.5 \mathrm{~mm}$ IBMX, $10 \mu \mathrm{g} / \mathrm{mL}$ insulin, $0.25 \mu \mathrm{M}$ DEX and $10 \%$ FBS). After two days, the culture medium was replaced with medium II (DMEM containing $10 \mu \mathrm{g} / \mathrm{mL}$ insulin and $10 \%$ FBS). After another two days, the cells were cultured in medium III (DMEM containing only 10\% FBS). The cells were used at $8 \mathrm{~d}$ after the initiation of differentiation. For adipogenesis studies, 3T3-L1 preadipocytes were treated with or without Cirsium japonicum flavones and GW9662 at the indicated concentrations in DMEM containing 10\% FBS and insulin $(1.0 \mu \mathrm{g} / \mathrm{mL})$ for $9 \mathrm{~d}$. Culture medium was replaced every $3 \mathrm{~d}$ with fresh medium containing $1.0 \mu \mathrm{g} / \mathrm{mL}$ insulin and $10 \%$ FBS with or without Cirsium japonicum flavones and GW9662. Measurement of intracellular lipid accumulation using Oil Red O staining was then performed to monitor the differentiation of preadipocytes to adipocytes. Briefly, cells at $9 \mathrm{~d}$ after the initiation of differentiation were fixed with $3 \%$ formaldehyde in PBS for $30 \mathrm{~min}$ at room temperature, washed three times with PBS and stained with filtered $0.3 \%$ Oil Red $\mathrm{O}$ in $55 \%$ isopropanol for $1 \mathrm{~h}$. Cells were washed three times with distilled water and photographed under a microscope. Lipids and Oil Red $\mathrm{O}$ were extracted with isopropanol and used for assaying the absorbance at a wavelength of $520 \mathrm{~nm}$.

Glucose Uptake Fully differentiated 3T3-L1 preadipocytes in 96-well plates were incubated with the indicated concentrations of Cirsium japonicum flavones for $48 \mathrm{~h}$. The cells were then washed twice and incubated with serum-free
DMEM with low glucose. After $3 \mathrm{~h}$, the cells were incubated with buffer II (118 mM NaCl, $4.7 \mathrm{~mm} \mathrm{KCl}, 1.0 \mathrm{~mm} \mathrm{CaCl}_{2}$, $1.0 \mathrm{~mm} \mathrm{MgSO}_{4}, 25 \mathrm{~mm} \mathrm{Na} \mathrm{HPO}_{4}, 1.2 \mathrm{~mm} \mathrm{KH} \mathrm{KO}_{4}, 0.5 \% \mathrm{BSA}$, $20 \mathrm{~mm} N$-(2-hydroxyethyl)piperazine- $N^{\prime}$-2-ethanesulfonic acid (Hepes), $2 \mathrm{~mm}$ sodium pyruvate, $0.1 \mathrm{~mm}\left[2-{ }^{3} \mathrm{H}\right]$ deoxyglucose, $\mathrm{pH}$ 7.4) supplemented with the indicated concentrations of Cirsium japonicum flavones in the presence or absence of $0.1 \mu \mathrm{M}$ insulin for $30 \mathrm{~min}$. After three washes with cold $\left[2-{ }^{3} \mathrm{H}\right]-$ deoxyglucose-free buffer II, cells were solubilized in $0.1 \%$ sodium dodecyl sulfate (SDS) and the radioactivity was determined in a scintillation counter. Glucose uptake was expressed as the degree of increase compared with basal 3T3-L1 cells and normalized against protein concentration in each sample.

Quantitative RT-PCR Total RNA was extracted from cells with Trizol reagent. After RNase-free DNase I digestion, mRNA was prepared by purifying total RNA with Qiagen RNeasy MinElute cleanup kit. The purified mRNA was then reverse-transcribed to cDNA using random primers and a reverse transcription system. Quantitative real-time PCR was performed with QuantiTect SYBR Green RT-PCR Kit and the fluorescence values were converted into threshold cycle values using ABI PRISM ${ }^{\circledR} 7000$ Sequence Detector Program according to the manufacturer's protocol. PCR amplifications were carried out as follows: 1 cycle for $10 \mathrm{~min}$ at $94^{\circ} \mathrm{C}$, followed by 35 cycles of $94^{\circ} \mathrm{C}$ for $15 \mathrm{~s}, 62^{\circ} \mathrm{C}$ for 30 and $72^{\circ} \mathrm{C}$ for $45 \mathrm{~s}$. $\beta$-Actin mRNA was used as an internal control to normalize the determined mRNA levels. Primers were designed as follows: adiponectin, 5'-GTGCAGGGTTGGATGGCAGG-3' and 5'-ATGATTCTGTTGGTTGTAGAAG-3'; GLUT4， 5'-GTG ACTGGAACACTGGTCCTAG-3' and 5'-GAAAGGAAGAGA TCATGCCAC-3'; $\beta$-actin, $5^{\prime}$-AGAAGATTTGGCACCACA CTTTC-3' and 5'-GAGGTAGTCTGTCAGGTCCCG-3'. All assays were performed in triplicate.

Preparation of Cell Extracts and Western Blot Analysis Cells were washed with ice-cold PBS, scraped, collected, lysed in ice-cold buffer I and centrifuged at $15000 \times \boldsymbol{g}$ for $20 \mathrm{~min}$ at $4^{\circ} \mathrm{C}$. Supernatants were saved and stored at $-80^{\circ} \mathrm{C}$. For subcellular fractionation, cells were lysed in buffer III (0.25 $\mathrm{m}$ sucrose, $2 \mathrm{~mm}$ EDTA, $1 \mathrm{~mm}$ phenylmethylsulfonyl fluoride (PMSF) and $10 \mathrm{~mm}$ Tris- $\mathrm{HCl}, \mathrm{pH}$ 7.4). The lysates were centrifuged at $750 \times \boldsymbol{g}$ for $15 \mathrm{~min}$, and the supernatants were centrifuged at $12000 \times \boldsymbol{g}$ for $20 \mathrm{~min}$ to isolate the crude plasma membrane fraction as the pellets. The supernatants were collected as the cytosolic fraction and the crude plasma membrane pellets were re-suspended in buffer III. Protein concentrations were measured using the Pierce ${ }^{\circledR}$ BCA Protein Assay kit. Samples with equal amount of protein were denatured, subjected to $10 \%$ SDS-PAGE and transferred to nitrocellulose membranes. Membranes were incubated overnight at $4^{\circ} \mathrm{C}$ with the rabbit anti-GLUT4, adiponectin or GAPDH antibodies in PBS containing 5\% (w/v) BSA. Membranes were washed three 
times and incubated with the goat anti-rabbit IgG conjugated to HRP in PBS containing 5\% (w/v) BSA. The blots were developed by enhanced chemiluminescence.

Statistical Analysis All quantitative data are representative of at least three independent experiments, and expressed as means \pm S.E. The statistical significance of differences between the data pairs was evaluated by analysis of variance (ANOVA).

\section{RESULTS}

Cirsium japonicum Flavones Activate PPAR $y$ It has been reported that Cirsium japonicum flavones showed an antidiabetic effect in diabetic rats. ${ }^{22}$ To study whether the Cirsium japonicum flavones-improved adiponectin expression and glucose metabolism in diabetic rats ${ }^{22}$ is related to the PPAR $\gamma$ pathway, we explored the effects of pectolinarin and DDMF on PPAR $\gamma$ activity in 3T3-L1 preadipocytes. Preadipocytes transfected with PPAR $\gamma$-luciferase reporter gene were treated with pectolinarin or DDMF at the indicated concentrations in the absence or presence of the PPAR $\gamma$ antagonist, GW9662. The PPAR $\gamma$ agonist, rosiglitazone, was used here as a positive control. Treatment of preadipocytes with pectolinarin or DDMF significantly activated PPAR $\gamma$ in a dose-dependent manner, which was inhibited by co-treatment with the PPAR $\gamma$ specific antagonist, GW9662 (Fig. 2A). Moreover, both quantitative RT-PCR analysis and western blot data showed that the expression of PPAR $\gamma$ target genes such as adiponectin and GLUT4 increased accordingly in pectolinarin or DDMFtreated adipocytes (Figs. 2B-D), which was also inhibited by GW9662. Because some compounds from other natural plants have been reported to be the ligand of PPAR $\gamma,{ }^{14,15)}$ we tried to determine the affinity of pectolinarin and DDMF for PPAR $\gamma$. However, there was no detectable binding of pectolinarin and DDMF to PPAR $\gamma$ (data not shown here). These findings indicate that Cirsium japonicum flavones are positive activators of PPAR $\gamma$, and possibly function upstream of PPAR $\gamma$.

Cirsium japonicum Flavones Promote Adipocyte Differentiation of 3T3-L1 Cells It is known that PPAR $\gamma$ activation is a key process during adipocyte differentiation. ${ }^{23}$ Based on this, a number of compounds from natural plants are being developed for pharmacological interventions for obesityrelated diabetes treatment. ${ }^{14-18)}$ Because Cirsium japonicum flavones induced PPAR $\gamma$ activation, especially up-regulating the expression of the PPAR $\gamma$ target gene adiponectin, which is involved in the induction of adipocyte differentiation and lipid metabolism, we investigated the effects of pectolinarin and DDMF on adipocyte differentiation of 3T3-L1 cells. As shown in Fig. 3, both pectolinarin and DDMF promoted the differentiation of 3T3-L1 preadipocytes to adipocytes in a dose-dependent manner. The optical densities of the Oil Red $\mathrm{O}$-stained extractions from cells treated with pectolinarin at concentrations of $1.0 \mu \mathrm{M}, 10 \mu \mathrm{M}$ and $50 \mu \mathrm{M}$, increased by $22 \%$, $78 \%$ and $98 \%$, respectively $(p<0.05)$. Treatment of $3 \mathrm{~T} 3-\mathrm{L} 1$ preadipocytes with $1.0 \mu \mathrm{M}, 10 \mu \mathrm{M}$ and $50 \mu \mathrm{M}$ DDMF resulted in $17 \%, 61 \%$ and $87 \%$ increase in the optical densities of the Oil Red O-stained extractions, respectively $(p<0.05)$. The positive control, PPAR $\gamma$ agonist rosiglitazone $(1.0 \mu \mathrm{M})$, also significantly promoted adipocyte differentiation of 3T3-L1 preadipocytes $(p<0.05)$. To further confirm the effect of Cirsium japonicum flavones as a PPAR $\gamma$ activator and to elucidate at which level
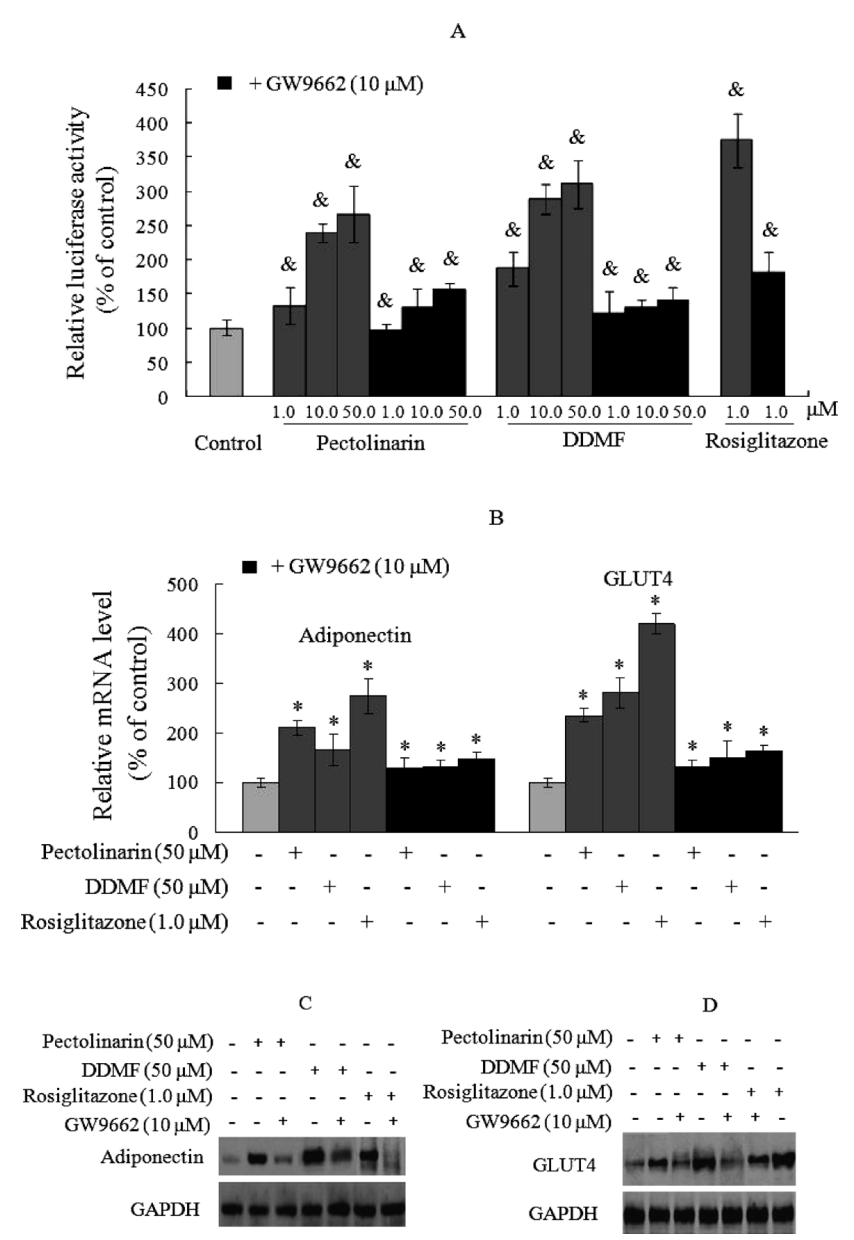

Fig. 2. Effects of Cirsium japonicum Flavones on PPAR $\gamma$ Activation

(A) 3T3-L1 preadipocytes transfected with PPAR $\gamma$-luciferase reporter plasmid and $\beta$-gal plasmid were treated with or without Cirsium japonicum flavones at the indicated concentrations for $24 \mathrm{~h}$ and then collected for lysate preparation. The luciferase activity in the lysate was assayed. Values are presented as means \pm S.E. ${ }^{\&} p<0.05$ vs. the control. (B) Total RNA was extracted from 3T3-L1 preadipocytes treated with Cirsium japonicum flavones and used for quantitative RT-PCR analysis of adiponectin and GLUT4 using ABI PRISM ${ }^{\circledR} 7000$ Sequence Detector Program. ${ }^{*} p<0.05 v s$. the control group not treated with Cirsium japonicum flavones or with rosiglitazone. (C, D) Total proteins prepared from Cirsium japonicum flavones-treated 3T3-L1 preadipocytes were separated by 10\% SDS-PAGE and then subjected to Western blot analysis of adiponectin and GLUT4. Cirsium japonicum flavones induced PPAR $\gamma$ activation in a dose-dependent manner and the expression of the PPAR $\gamma$ target genes, adiponectin and GLUT4. These effects were inhibited by GW9662.

in the PPAR $\gamma$ signaling pathway this activation occurs, we examined the effects of the PPAR $\gamma$ antagonist, GW9662, on Cirsium japonicum flavones-induced differentiation. As shown in Fig. 3, the lipid accumulation in 3T3-L1 preadipocytes treated with Cirsium japonicum flavones, insulin and GW9662 was greatly reduced, compared with the 3T3-L1 preadipocytes that were not treated with GW9662. Taken together, these results indicate that Cirsium japonicum flavones enhance adipocyte differentiation via inducing PPAR $\gamma$ activation.

Cirsium japonicum Flavones Increase Basal and InsulinStimulated Glucose Uptake in 3T3-L1 Adipocytes It has been reported that PPAR $\gamma$ activation plays an important role in glucose metabolism, especially in enhancing glucose uptake in 3T3-L1 adipocytes. ${ }^{24)}$ Next, we investigated the effects of Cirsium japonicum flavones on glucose metabolism and insulin sensitivity in 3T3-L1 adipocytes. As shown in Fig. 4, Cirsium japonicum flavones enhanced both basal and insulin-stimulated glucose consumption in a dose-dependent 
A

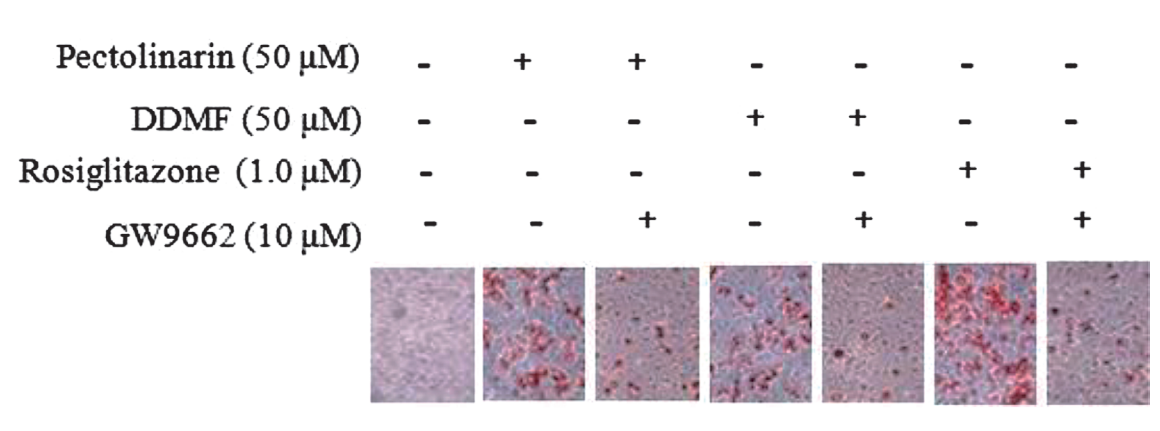

B

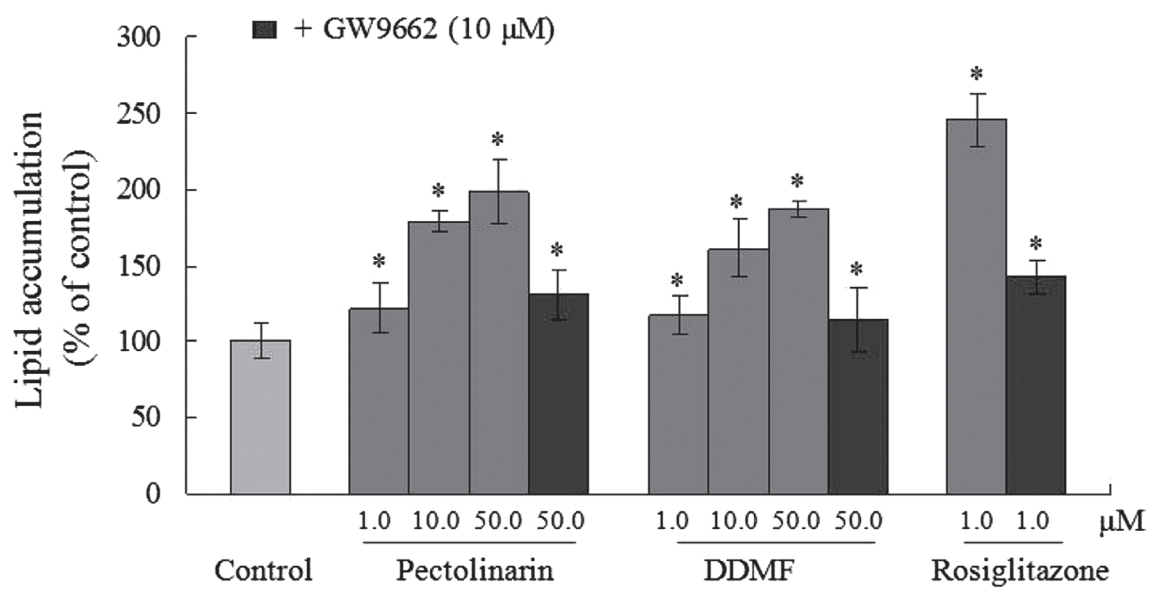

Fig. 3. Effects of Cirsium japonicum Flavones on Adipocyte Differentiation of 3T3-L1 Preadipocytes

3T3-L1 preadipocytes were incubated in medium containing insulin $(1.0 \mu \mathrm{g} / \mathrm{mL})$ for nine days with or without the indicated concentrations of Cirsium japonicum flavones or GW9662. Cells were fixed and stained with Oil Red O. (A) The Oil Red O-stained adipocytes were photographed at a 100× magnification under a microscope. (B) Lipids were extracted using isopropanol, and the Oil Red O was then analyzed at a wavelength of $520 \mathrm{~nm}$. Values are presented as means \pm S.E. $* p<0.05 v s$. the control.

manner in 3T3-L1 adipocytes. Treatment with pectolinarin at concentrations of $1.0 \mu \mathrm{M}, 10 \mu \mathrm{M}$ and $50 \mu \mathrm{M}$ increased the basal glucose uptake by $31 \%, 56 \%$, and $67 \%(p<0.05)$, respectively, compared with the vehicle-treated cells. The basal glucose uptake in $1.0 \mu \mathrm{M}, 10 \mu \mathrm{M}$ and $50 \mu \mathrm{m}$ DDMF-treated cells increased by $25 \%, 45 \%$, and $60 \%(p<0.05)$, respectively. The insulin-stimulated glucose uptake increased by $13 \%, 75 \%$ and $131 \%(p<0.01)$ in pectolinarin-treated cells at concentrations of $1.0 \mu \mathrm{M}, 10 \mu \mathrm{M}$ and $50 \mu \mathrm{M}$, respectively, and by $23 \%, 77 \%$ and $125 \%(p<0.01)$ in DDMF-treated cells at concentrations of $1.0 \mu \mathrm{M}, 10 \mu \mathrm{M}$ and $50 \mu \mathrm{M}$, respectively. These effects of pectolinarin and DDMF were significantly inhibited by GW9662. In addition, the GLUT4 level in the plasma membrane increased after treatment with pectolinarin or DDMF. Because activation of phosphatidylinositol 3-kinase (PI3K) is necessary for glucose transport and GLUT4 translocation, ${ }^{25)}$ we examined the effects of wortmannin on Cirsium japonicum flavonesenhanced glucose uptake. The results show that $0.1 \mu \mathrm{M}$ wortmannin significantly inhibited both pectolinarin and DDMFstimulated glucose uptake and GLUT4 translocation (Fig. 4). These results indicate that Cirsium japonicum flavones increase both basal and insulin-stimulated glucose uptake in 3T3-L1 adipocytes, possibly through modulating the insulin signaling pathway.

\section{DISCUSSION}

Diabetes mellitus is considered to be a serious endocrine syndrome. Obesity is a risk factor for diabetes and hyperlipidemia, and the exploding prevalence of obesity-induced insulin resistance and T2DM has become a major public health problem worldwide. Adipose tissue has been identified as an endocrine organ, which secretes a series of bioactive molecules named adipocytokines, involved in maintaining metabolic homeostasis. ${ }^{26}$ Adipose tissue functions in insulin resistance syndrome through the production and secretion of adipocytokines, such as aP2, adiponectin, GLUT4, GLUT1, PPAR $\gamma$, plasminogen activator inhibitor-1 (PAI-1) and tumor necrosis factor- $\alpha(\mathrm{TNF}-\alpha)$, which are differentially expressed and regulated in enlarged adipocytes and small adipocytes. ${ }^{26,27)} \mathrm{Be}-$ cause dysregulation of the number of adipocytes greatly contributes to the development of obesity-related T2DM, positive regulation of adipocyte differentiation and adipogenesis is of great significance for preventing obesity-induced insulin resistance and T2DM. Conversion of preadipocytes to adipocytes is controlled by various regulators, especially $\operatorname{PPAR} \gamma$ which has been clinically validated for therapeutic interventions in treating T2DM. ${ }^{28)}$ More and more studies have shown that natural compounds work well in improving hyperglycemia and hypertriglyceridemia, most likely by remodeling the adipose tissue, whereby the number of large adipocytes decreases 


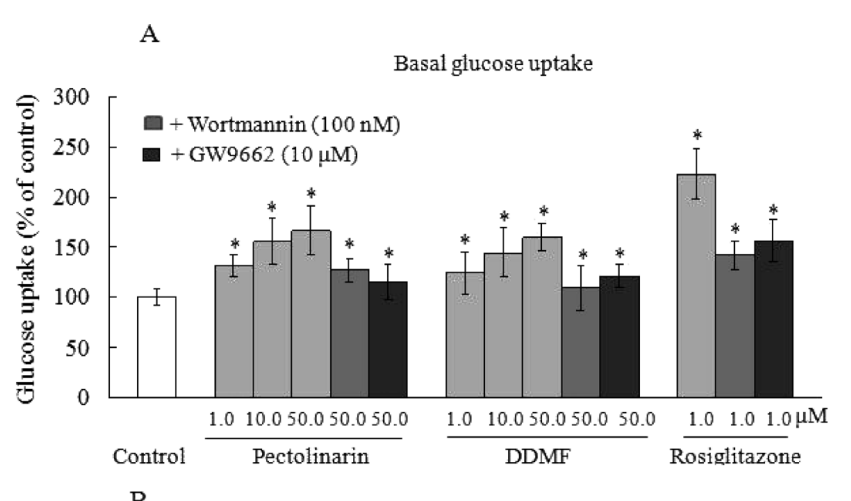

B

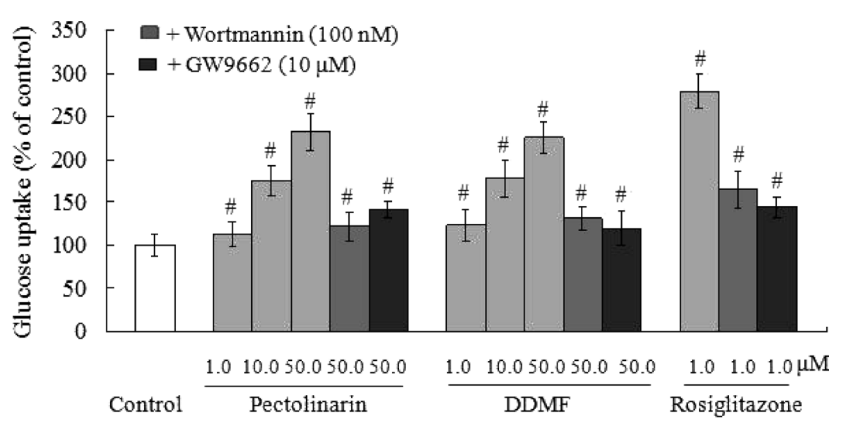

$\mathrm{C}$

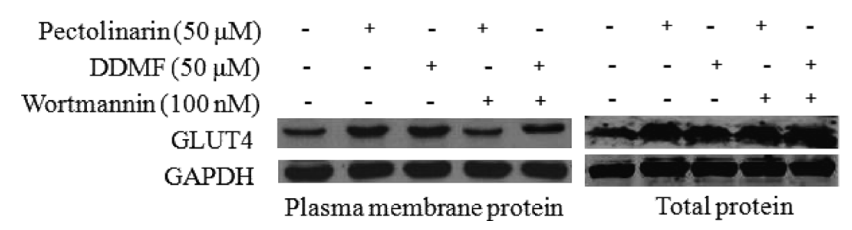

Fig. 4. Cirsium japonicum Flavones Increase Glucose Uptake in 3T3L1 Adipocytes via Modulation of the Insulin Signaling Pathway

Fully differentiated 3T3-L1 adipocytes were incubated with the indicated concentrations of Cirsium japonicum flavones in the presence or absence of wortmannin for $48 \mathrm{~h}$. (A, B) Glucose uptake was determined in the absence or presence of $100 \mathrm{~nm}$ insulin by assaying the radioactivity of $\left[2-{ }^{3} \mathrm{H}\right]$ deoxyglucose in a scintillation counter. Values are presented as means \pm S.E. $* p<0.05 v s$. the control. ${ }^{\#} p<0.01$ $v s$. the control treated with insulin alone. (C) Plasma membrane protein and total protein were prepared and subjected to SDS-PAGE. The plasma membrane GLUT4 levels and total GLUT4 expression were detected separately.

while that of small and/or insulin-sensitive cells increases. ${ }^{29-31)}$ Cirsium japonicum flavones have been reported to improve glucose and lipid metabolic homeostasis in diabetic rats. ${ }^{22)}$ In the present study, two Cirsium japonicum flavones, pectolinarin and DDMF, induced PPAR $\gamma$ activation in a dose-dependent manner, as demonstrated by luciferase reporter gene assay. The adipogenic genes adiponectin and GLUT4, which are also PPAR $\gamma$ target genes, showed up-regulated expression in pectolinarin or DDMF-treated 3T3-L1 preadipocytes. As a result, the differentiation of 3T3-L1 preadipocytes to adipocytes and adipogenesis were significantly enhanced by pectolinarin and DDMF. These Cirsium japonicum flavones-induced events were inhibited by cotreatment with GW9662. In the ligand binding experiment, there was no observed affinity of pectolinarin and DDMF to PPAR $\gamma$ (data not shown). These results indicate that Cirsium japonicum flavones promote adipocyte differentiation through inducing PPAR $\gamma$ activation, wherein they possibly function upstream of PPAR $\gamma$.

Dysregulation of glucose and lipid metabolism is a major feature of T2DM. It is known that adiponectin and GLUT4 positively regulate glucose uptake in adipocytes.7) Adiponectin is an adipose tissue-derived hormone of the Clq/TNF-superfamily, which is highly abundant in human serum and shows an inverse correlation with body mass index. ${ }^{26,32)}$ Higher adiponectin levels are associated with a lower risk for type 2 diabetes, and the plasma adiponectin concentration is inversely correlated with the severity of insulin resistance. ${ }^{33)}$ Full-length and globular adiponectin promote the translocation of GLUT4 to the plasma membrane. ${ }^{34)}$ Both basal and insulin-stimulated glucose transport in insulin sensitive tissues are closely related to the expression of GLUT4 and its translocation to the plasma membrane. ${ }^{35)}$ PPAR $\gamma$ activators are known to increase glucose transport in adipocytes by directly regulating the expression of PPAR $\gamma$ target genes such as adiponectin and GLUT4, which are involved in glucose metabolism. ${ }^{13,36)}$ In accordance with the finding that Cirsium japonicum flavones activated PPAR $\gamma$, in Cirsium japonicum flavones-treated adipocytes the expression of adiponectin and GLUT4 and GLUT4 translocation to the plasma membrane were up-regulated. As a result, Cirsium japonicum flavones increased both basal and insulinstimulated glucose uptake, with maximal stimulation at $50 \mathrm{~mm}$ for both pectolinarin and DDMF. It is known that activation of PI3K is a major event in the insulin signaling cascade that leads to GLUT4 translocation. ${ }^{25}$ ) Binding of insulin to insulin receptor (IR) results in autophosphorylation of the intracellular tyrosine residues of the IR $\beta$-subunit, which leads to the activation of downstream signaling molecules such as PI3K and GLUT4 translocation to the plasma membrane. ${ }^{25,37)}$ Here, we found that Cirsium japonicum flavones-increased basal and insulin-stimulated glucose uptake was blocked by the PI3K inhibitor, wortmannin. At the same time, the ratio of plasma membrane GLUT4 to total GLUT4 increased after Cirsium japonicum flavones treatment, which was inhibited by wortmannin. These results suggest that Cirsium japonicum flavones may modulate the insulin signaling pathway, thereby positively regulating glucose uptake in adipocytes. However, further studies are required to clarify whether there are alternative pathways responsible for the Cirsium japonicum flavones-induced effects.

In summary, we found that Cirsium japonicum flavones enhanced adipocyte differentiation by increasing the PPAR $\gamma$ transcriptional activity. In addition, Cirsium japonicum flavones promoted both basal and insulin-stimulated glucose uptake in 3T3-L1 adipocytes, possibly through increased adiponectin and GLUT4 expression and GLUT4 translocation, which was at least partially related to the modulation of insulin signaling. Our research further demonstrates that Cirsium japonicum flavones have the potential of being used as an active pharmaceutical ingredient for treating diabetes.

Acknowledgments This work was supported by Grants from Natural Science Foundation of Zhejiang (No. Y2110853 and No. Z2100435), Zhejiang Science and Technology Program (No. 2010C33173), and National Natural Science Foundation of China (No. 31070322).

\section{REFERENCES}

1) Travers ME, McCarthy MI. Type 2 diabetes and obesity: genomics and the clinic. Hum. Genet., 130, 41-58 (2011).

2) Jafar-Mohammadi B, McCarthy MI. Genetics of type 2 diabetes 
mellitus and obesity - a review. Ann. Med., 40, 2-10 (2008).

3) Siersbaek R, Nielsen R, Mandrup S. PPARgamma in adipocyte differentiation and metabolism-novel insights from genome-wide studies. FEBS Lett., 584, 3242-3249 (2010).

4) Kamon J, Yamauchi T, Kadowaki T. PPAR family (PPAR alpha, PPAR delta, PPAR gamma). Nippon Rinsho, 60 (Suppl. 7), 593-600 (2002).

5) Brun RP, Spiegelman BM. PPAR gamma and the molecular control of adipogenesis. J. Endocrinol., 155, 217-218 (1997).

6) Lehrke M, Lazar MA. The many faces of PPARgamma. Cell, 123, 993-999 (2005).

7) Rabe K, Lehrke M, Parhofer KG, Broedl UC. Adipokines and insulin resistance. Mol. Med., 14, 741-751 (2008).

8) Leff T, Mathews ST, Camp HS. Review: peroxisome proliferatoractivated receptor-gamma and its role in the development and treatment of diabetes. Exp. Diabesity Res., 5, 99-109 (2004).

9) Barroso I, Gurnell M, Crowley VE, Agostini M, Schwabe JW, Soos MA, Maslen GL, Williams TD, Lewis H, Schafer AJ, Chatterjee VK, O'Rahilly S. Dominant negative mutations in human PPARgamma associated with severe insulin resistance, diabetes mellitus and hypertension. Nature, 402, 880-883 (1999).

10) Doney AS, Fischer B, Leese G, Morris AD, Palmer CN. Cardiovascular risk in type 2 diabetes is associated with variation at the PPARG locus: a Go-DARTS study. Arterioscler. Thromb. Vasc. Biol., 24, 2403-2407 (2004).

11) Monajemi H, Zhang L, Li G, Jeninga EH, Cao H, Maas M, Brouwer CB, Kalkhoven E, Stroes E, Hegele RA, Leff T. Familial partial lipodystrophy phenotype resulting from a single-base mutation in deoxyribonucleic acid-binding domain of peroxisome proliferatoractivated receptor-gamma. J. Clin. Endocrinol. Metab., 92, 16061612 (2007).

12) Semple RK, Chatterjee VK, O'Rahilly S. PPAR gamma and human metabolic disease. J. Clin. Invest., 116, 581-589 (2006).

13) Staels B, Fruchart JC. Therapeutic roles of peroxisome proliferatoractivated receptor agonists. Diabetes, 54, 2460-2470 (2005).

14) Han KL, Jung MH, Sohn JH, Hwang JK. Ginsenoside 20Sprotopanaxatriol (PPT) activates peroxisome proliferator-activated receptor gamma (PPARgamma) in 3T3-L1 adipocytes. Biol. Pharm. Bull., 29, 110-113 (2006).

15) Choi SS, Cha BY, Iida K, Lee YS, Yonezawa T, Teruya T, Nagai $\mathrm{K}$, Woo JT. Artepillin C, as a PPAR $\gamma$ ligand, enhances adipocyte differentiation and glucose uptake in 3T3-L1 cells. Biochem. Pharmacol., 81, 925-933 (2011).

16) Yang Y, Shang W, Zhou L, Jiang B, Jin H, Chen M. Emodin with PPARgamma ligand-binding activity promotes adipocyte differentiation and increases glucose uptake in 3T3-L1 cells. Biochem. Biophys. Res. Commun., 353, 225-230 (2007).

17) Shin DW, Kim SN, Lee SM, Lee W, Song MJ, Park SM, Lee TR, Baik JH, Kim HK, Hong JH, Noh M. (-)-Catechin promotes adipocyte differentiation in human bone marrow mesenchymal stem cells through PPAR gamma transactivation. Biochem. Pharmacol., 77, 125-133 (2009).

18) Choi SS, Cha BY, Lee YS, Yonezawa T, Teruya T, Nagai K, Woo JT. Magnolol enhances adipocyte differentiation and glucose uptake in 3T3-L1 cells. Life Sci., 84, 908-914 (2009).

19) Liu SJ, Luo X, Li DX, Zhang J, Qiu DL, Liu W, She L, Yang ZR. Tumor inhibition and improved immunity in mice treated with flavone from Cirsium japonicum DC. Int. Immunopharmacol., 6, 1387-1393 (2006).

20) Jeong M, Jung HA, Choi JS. Comparative antioxidant activity and HPLC profiles of some selected Korean thistles. Arch. Pharm. Res., 31, 28-33 (2008).
21) Yin J, Heo SI, Wang MH. Antioxidant and antidiabetic activities of extracts from Cirsium japonicum roots. Nutr. Res. Pract., 2 , 247-251 (2008).

22) Liao ZY, Chen XL, Wu MJ. Antidiabetic effect of flavones from Cirsium japonicum DC in diabetic rats. Arch. Pharm. Res., 33, 353-362 (2010).

23) Spiegelman BM. PPAR-gamma: adipogenic regulator and thiazolidinedione receptor. Diabetes, 47, 507-514 (1998).

24) Tafuri SR. Troglitazone enhances differentiation, basal glucose uptake, and Glut1 protein levels in 3T3-L1 adipocytes. Endocrinology, 137, 4706-4712 (1996).

25) Khan AH, Pessin JE. Insulin regulation of glucose uptake: a complex interplay of intracellular signalling pathways. Diabetologia, 45, 1475-1483 (2002).

26) Guerre-Millo M. Adipose tissue and adipokines: for better or worse. Diabetes Metab., 30, 13-19 (2004).

27) Yamauchi T, Kamon J, Waki H, Murakami K, Motojima K, Komeda K, Ide T, Kubota N, Terauchi Y, Tobe K, Miki H, Tsuchida A, Akanuma Y, Nagai R, Kimura S, Kadowaki T. The mechanisms by which both heterozygous peroxisome proliferator-activated receptor gamma (PPARgamma) deficiency and PPARgamma agonist improve insulin resistance. J. Biol. Chem., 276, 41245-41254 (2001).

28) Sheng X, Zhang Y, Gong Z, Huang C, Zang YQ. Improved insulin resistance and lipid metabolism by cinnamon extract through activation of peroxisome proliferator-activated receptors. PPAR Res., 2008, 581348 (2008).

29) de Souza CJ, Eckhardt M, Gagen K, Dong M, Chen W, Laurent D, Burkey BF. Effects of pioglitazone on adipose tissue remodeling within the setting of obesity and insulin resistance. Diabetes, 50, 1863-1871 (2001).

30) Yokoi H, Mizukami H, Nagatsu A, Ohno T, Tanabe H, Inoue M. Peroxisome proliferator-activated receptor gamma ligands isolated from adlay seed (Coix lacryma-jobi L. var. ma-yuen STAPF.). Biol. Pharm. Bull., 32, 735-740 (2009).

31) Zhang WY, Lee JJ, Kim IS, Kim Y, Park JS, Myung CS. 7-O-methylaromadendrin stimulates glucose uptake and improves insulin resistance in vitro. Biol. Pharm. Bull., 33, 1494-1499 (2010).

32) Arita Y, Kihara S, Ouchi N, Takahashi M, Maeda K, Miyagawa J, Hotta K, Shimomura I, Nakamura T, Miyaoka K, Kuriyama H, Nishida M, Yamashita S, Okubo K, Matsubara K, Muraguchi M, Ohmoto Y, Funahashi T, Matsuzawa Y. Paradoxical decrease of an adipose-specific protein, adiponectin, in obesity. Biochem. Biophys. Res. Commun., 257, 79-83 (1999).

33) Li S, Shin HJ, Ding EL, van Dam RM. Adiponectin levels and risk of type 2 diabetes: a systematic review and meta-analysis. JAMA, 302, 179-188 (2009).

34) Fruebis J, Tsao TS, Javorschi S, Ebbets-Reed D, Erickson MR, Yen FT, Bihain BE, Lodish HF. Proteolytic cleavage product of $30-\mathrm{kDa}$ adipocyte complement-related protein increases fatty acid oxidation in muscle and causes weight loss in mice. Proc. Natl. Acad. Sci. U.S.A., 98, 2005-2010 (2001).

35) Carvalho E, Kotani K, Peroni OD, Kahn BB. Adipose-specific overexpression of GLUT4 reverses insulin resistance and diabetes in mice lacking GLUT4 selectively in muscle. Am. J. Physiol. Endocrinol. Metab., 289, E551-E561 (2005).

36) Ribon V, Johnson JH, Camp HS, Saltiel AR. Thiazolidinediones and insulin resistance: peroxisome proliferatoractivated receptor gamma activation stimulates expression of the CAP gene. Proc. Natl. Acad. Sci. U.S.A., 95, 14751-14756 (1998).

37) Watson RT, Kanzaki M, Pessin JE. Regulated membrane trafficking of the insulin-responsive glucose transporter 4 in adipocytes. Endocr. Rev., 25, 177-204 (2004). 